\title{
PENGUJIAN EFIKASI CENDAWAN Metarhizium anisopliae s.l. PADA HAMA ULAT API (Setothosea asigna) DI LABORATORIUM
}

\author{
Yuni Dzulhia'), F. X. Susilo' ${ }^{2)}$, Agus M. Hariri²),Yuyun Fitriana ${ }^{2)}$ \\ ${ }^{1}$ Mahasiswa Jurusan Agroteknologi Fakultas Pertanian Universitas Lampung \\ ${ }^{2}$ Dosen Jurusan Agroteknologi Fakultas Pertanian Universitas Lampung \\ Jln. Prof. Dr. Soemantri Brojonegoro No. 1 Bandar Lampung 35145 \\ E-mail : yunidzulhia@icloud.com
}

\begin{abstract}
ABSTRAK
Penelitian ini bertujuan untuk mengetahui pertumbuhan dan perkembangan M.anisopliae s.l.dan efikasi cendawan M.anisopliae s.l. terhadap ulat api.Penelitian dilakukan di Laboratorium Bioteknologi Pertanian, Fakultas Pertanian, Universitas Lampung. Metode penelitian meliputi uji pertumbuhan dan perkembangan M. anisopliae s.l. secara in vitro dan uji efikasi $M$. anisopliae s.l. pada ulat api. Percobaan uji pertumbuhan dan perkembangan M.anisopliae s.l. secara in vitromenggunakan Rancangan Acak Lengkap (RAL) dan diulang 4 kali. Uji efikasi M. anisopliae s.l. pada ulat api menggunakan analisis probit untuk menentukan nilai $\mathrm{LC}_{50} \mathrm{dan}_{\mathrm{LT}}$ dari isolat Myf 51 dan Myf B. Perlakuan terdiri dari M.anisopliae s.l. B (wildtype), M.anisopliae s.l.1 (mutan), M.anisopliae s.l.42 (mutan), dan M.anisopliae s.l. 51 (mutan). Hasil penelitian menunjukkan bahwa isolat mutan Myf51, Myf 42, dan Myf 1 mampu tumbuh dan berkembang normal sebagaimana isolat MyfB (wildtype). Isolat Myf 51 (mutan) dan Myf B (wildtype) efektif mengendalikan 50\% ulat api dengan nilai LC ${ }_{50}$ Myf 51 sebesar 1,06 x $10^{5} \mathrm{konidia} / \mathrm{ml}$ dan LC $\mathrm{L}_{50}$ Myf B sebesar 2,92 x $10^{5} \mathrm{konidia} / \mathrm{ml}$ LT $_{50}$ Myf 51 dan Myf B terhadap ulat api relatif sama, yaitu pada kisaran 4,6 - 6,6 hari setelah aplikasi (hsa).
\end{abstract}

Kata kunci : efikasi, Metarhizium anisopliae s.l., Setothosea asigna, ulat api.

\section{PENDAHULUAN}

Kelapa sawit (Elaeis guineensis) mempunyai peranan penting pada perekonomian Indonesia.Pertama, kelapa sawit merupakan bahan utama pembuatan komoditas minyak goreng. Kedua, kelapa sawit sebagai salah satu komoditas andalan ekspor non migas. Ketiga, dalam proses produksi dan pengolahan kelapa sawit mampu menciptakan kesempatan kerja dan meningkatkan kesejahteraan masyarakat (Prawirosukarto et al., 2003).
Tanaman kelapa sawit mendapat gangguan organisme pengganggu tanaman. Salah satunya ulat api (Setothosea asigna). Ulat apimerupakan hama yang yang menyerang daun kelapa sawit. Ulat api memakan daun kelapa sawit mulai dari permukaan bawah daun hingga daun bagian atas (Buana dan Siahaan, 2003).

Serangan ulat apidapat mengakibatkan penurunan produktivitas bahkan kegagalan panen kelapa sawit. Di Indonesia, serangan ulat api pada kelapa sawit dapat mengakibatkan penurunan produksi 
sampai 70\% pada tahun pertama. Jika serangan berat, tanaman dapat tidak berbuah selama 1-2 tahun berikutnya (Susanto et al., 2012).

Pada perkebunan kelapa sawit, masalah ulat api umumnya diatasi dengan menggunakan insektisida kimia. Penggunaan insektisida kimia secara kurang bijaksana dapat menimbulkan berbagai dampak negatif. Dampak yang ditimbulkan yaitu pada perkebunan kelapa sawit dapat terjadi ledakan populasi (resurgensi) ulat api. Selain itu ulat api menjadi resisten terhadap insektisida kimia (Prawirosukarto et al., 2003).

Penggunaan cendawan entomopatogen mungkin dapat menjadi alternatif penggunaan insektisida kimia.Penggunaan cendawan entomopatogen diharapkan dapat mengendalikan hama tanpa menimbulkan masalah lingkungan. Salah satu cendawan entomopatogen yang potensial untuk mengendalikan hama ulat api ialah Metarhiziumanisopliae.

Cendawan M.anisopliae s.l. mutan merupakan cendawan yang mengalami peristiwa mutasi. Peristiwa mutasi dapat disebabkan oleh pemaparan sinar ultra violet (UV), berkas elektron, ion beam, gamma ray, dan bahan kimia ethyl methane sulfote (EMS). Metarhizium sp. mutan dengan pemaparan sinar ultra violet dilaporkan mampu meningkatkan efikasi Metarhizium sp. terhadap Crocidolomia pavonana Fabricius (Lepidoptera : Pyralidae) (Fitrah, 2009). Informasi tentang kemampuan $M$. anisopliae s.l. mutan dalam menginfeksi ulat api belum pernah dilaporkan.

Cendawan M.anisopliae telah dilaporkan dapat menginfeksi serangga - serangga hama dari golongan Lepidoptera (ulat) seperti S. litura dan $S$. exigua (Desyanti et al.,2007). Informasi tentang kemampuan M. anisopliae s.l. dalam menginfeksi ulat api belum pernah dilaporkan. Oleh karena itu, penelitian ini dilakukan untuk mengetahui pertumbuhan dan perkembangan M.anisopliae s.l mutan vs wildtype dan mengetahui efikasi cendawan M.anisopliae s.l. terhadap ulat api.

\section{METODE PENELITIAN}

\section{Tempat dan Waktu}

Ulat api diambil dari perkebunan kelapa sawit Tanjung Sari, Natar, Lampung Selatan. Ulat api diaplikasikan cendawan M. anisopliae s.l. di Laboratorium Bioteknologi Pertanian, Fakultas Pertanian, Universitas Lampung. Penelitian ini dilaksanakan pada bulan November 2016 sampai Mei 2017.

\section{Bahan dan Alat}

Bahan-bahan yang digunakan pada penelitian ini adalah cendawanM.anisopliae s.l., ulat api, media PSA, Tween 80, dan asam laktat.Alat-alat yang digunakan pada penelitian ini terdiri dari alat ukur, alat gelas, dan alat non gelas. Alat ukur yaitu haemocytometer, timbangan, dan penggaris. Alat gelas yaitu cawan petri, tabung reaksi, erlenmeyer, spatula, drigalsky, dan bunsen. Alat non gelas yaitu jarum ose, autoklaf, mikroskop, laminar air flow, shaker,mikropipet, borgabus, stoples, panci, sprayer (alat semprot), kompor, kertas label, alumunium foil, plastik warp, kain kasa, karet, pisau, tisu, dan nampan. 
Uji Pertumbuhan dan Perkembangan

\section{M.anisopliae s.l. secara In Vitro}

Uji pertumbuhan dan perkembangan cendawan M. anisopliae s.l. secara in vitro menggunakan Rancangan Acak Lengkap (RAL) dengan 4 perlakuan yang diulang sebanyak 4 kali.Perlakuan terdiri dari $M$. anisopliae s.l. B (wildtype), M. anisopliae s.l. 1 (mutan), M. anisopliae s.l. 42 (mutan), M. anisopliae s.l. 51 (mutan).Variabel pengamatan yaitu pertumbuhan koloni M. anisopliae s.l. (mutan vs wildtype), kerapatan konidia M. anisopliae s.l. (mutan vs wildtype), dan persentase daya kecambah konidia $M$. anisopliae s.l. (mutan vs wildtype).

Pengamatan pertumbuhan koloniM.anisopliae s.l. (mutan vs wildtype) dilakukan dengan cara mengukur diameter cendawan secara vertikal dan horizontal.Diameter vertikal dan horizontal tersebut dijumlahkan dan dibagi dengan dua.Pengamatan dilakukan 1 hari setelah inokulasi selama 14 hari.

Pengamatan kerapatan konidia M. anisopliae s.l. (mutan vs wildtype) dilakukan dengan mengambil $1 \mathrm{ml}$ suspensi konidia, kemudian diteteskan pada haemocytometer.Perhitungan kerapatan konidia dilakukan dengan cara memilih kotak sedang yang terdapat pada haemocytometer sebanyak 5 kotak sedang, tiap kotak sedang tersebut dihitung nilai rataratanya.Penghitungan diulang sebanyak 4 kali.Kerapatan konidia yang terbentuk akandihitung dengan menggunakan rumus Gabriel \& Riyanto (1989, dalam Ratna 20ก4) sehaoai herikut.

$$
\mathrm{S}=\frac{\mathrm{t}}{\mathrm{n} \times 0,25} \times 10^{6}
$$

dengan catatan $\mathrm{S}=$ kerapatan konidia, $\mathrm{t}=$ jumlah konidia yang dihitung, $\mathrm{n}=$ jumlah kotak sampel yang dihitung, 0,25 = faktor koreksi.

Pengamatan daya kecambah konidia M.anisopliae s.l. (mutan vs wildtype) dilakukan dengan cara berikut. Suspensi konidia diinkubasi selama 16 jam di media PSA pada suhu ruang. Setelah itu, konidia M. anisopliae s.l. diamati di bawah mikroskop.Konidia dinyatakan berkecambah apabila panjang kecambah berukuran 2 kali diameter konidia (Espinel-Ingroff, 2000).Persentase daya kecambah konidia dapat dihitung menggunakan rumus sebagai berikut.

$$
\mathrm{V}=\frac{\mathrm{g}}{\mathrm{g}+\mathrm{u}} \times 100 \%
$$

dengan catatan $\mathrm{V}=$ perkecambahan konidia(viabilitas), $\mathrm{g}=$ jumlah konidia yang berkecambah, $\mathrm{u}=$ jumlah konidia yang tidak berkecambah.

\section{Uji Efikasi M.anisopliae s.l.pada Ulat Api}

Uji efikasi M.anisopliae s.l.pada ulat api dianalisis dengan metode analisis probit. Analisis probit dilakukan dengan menggunakan program statistik komputer (SPSS 16.0 for Windows). Data konsentrasi suspensiM.anisopliae s.l., jumlah serangga uji, dan jumlah serangga mati tiap perlakuan diolah untuk menentukan nilai $\mathrm{LC}_{50}$ dan $\mathrm{LT}_{50}$.

Variabel pengamatan yang diamati yaitu persentase kematian hamaulat api. Persentase kematian hama ulat api yang diduga terinfeksi cendawan M.anisopliae s.l.dilakukan pengamatan di bawah mikroskop. Pengamatan kematian ulat api secara mikroskopis bertujuan untuk memastikan kematian ulat 
api tersebut disebabkan oleh cendawanM.anisopliae

s.l. Persentase kematian ulat api dapat dihitung dengan rumus sebagai berikut.

Tingkat Kematian(\%)

$=\frac{\text { Jumlah hama yang mati }}{\text { Jumlah hama yang diamati }} \times 100 \%$

\section{Analisis Data}

Data yang diperoleh dari uji pertumbuhan dan perkembangan M. anisopliae s.l. dianalisis dengan uji statistika.Ragam diameter, kerapatan konidia dan perkecambahan M.anisopliae s.l. (mutan vs wildtype) diuji homogenitasnya dengan Uji Barlett.Setelah asumsi terpenuhi maka data dianalisis dengan sidik ragam dan perbedaan nilai tengah perlakuan dengan Uji Duncan Multiple Range Test (DMRT) 5\%.Data yang diperoleh dari uji efikasi M. anisopliae s.l. dianalisis dengan Uji Probit pada taraf nyata 5\%. Uji Probit dilakukan untuk menentukan $\mathrm{LT}_{50}$ dan $\mathrm{LC}_{50}$ dari isolat MyfB (wildtype) dan Myf 51 (mutan).

\section{HASIL DAN PEMBAHASAN}

Dari hasil perhitungan diameter koloni $M$. anisopliae s.l. * menunjukkan bahwa isolat mutan Myf 51, Myf 42, dan Myf 1 mampu tumbuh dalam keadaan normal. Isolat Myf 51 dan Myf 42 mampu tumbuh maksimum sebagaimana isolat Myf B (wildtype).Isolat Myf1 mampu tumbuh meskipun pertumbuhannya relatif rendah dari isolat Myf B (wildtype). Berdasarkan hasil DMRT 5\%, isolat Myf 51, Myf 42, dan Myf 1 pada 14 hsi masing-masing berbeda nyata dengan isolat Myf B (Tabel 1).

Dari hasil perhitungan kerapatan konidia $M$. anisopliae s.l. * menunjukkan bahwa isolat mutan Myf 51, Myf 42, dan Myf 1 mampu berkembang menghasilkan konidia sebagaimana isolat Myf B (wildtype). Isolat Myf 51 dan Myf 42 (mutan) mampu berkembang menghasilkan konidia relatif sama dengan isolat Myf B (wildtype). Sedangkan isolat Myf 1 (mutan) mampu berkembang menghasilkan konidia

Tabel 1. Diameter koloni M. anisopliae s.l. * pada media PSA

Diameter koloni M. anisopliae s.l. *(cm)

Isolat M. anisopliae s.l.*

\begin{tabular}{|c|c|c|c|c|c|c|}
\hline & 2 & 4 & 6 & 8 & 10 & 12 \\
\hline MyfB & $1,49 \mathrm{~b}$ & $2,24 \mathrm{bc}$ & $2,93 \mathrm{a}$ & $3,60 \mathrm{a}$ & $4,25 \mathrm{a}$ & $4,94 \mathrm{a}$ \\
\hline Myf 1 & $1,28 \mathrm{a}$ & $1,99 \mathrm{a}$ & $2,70 \mathrm{a}$ & $3,50 \mathrm{a}$ & $4,24 \mathrm{a}$ & $4,88 \mathrm{a}$ \\
\hline Myf 42 & $1,45 \mathrm{~b}$ & $2,21 \mathrm{ab}$ & $2,98 \mathrm{a}$ & $3,79 \mathrm{a}$ & $4,41 \mathrm{a}$ & $5,09 \mathrm{a}$ \\
\hline Myf 51 & $1,68 \mathrm{c}$ & $2,61 \mathrm{c}$ & $3,44 \mathrm{~b}$ & $4,16 \mathrm{~b}$ & $4,90 \mathrm{~b}$ & $5,50 \mathrm{~b}$ \\
\hline F hitung & 10,90 & 8,51 & 7,14 & 5,76 & 5,80 & 7,70 \\
\hline
\end{tabular}

Keterangan : Angka-angka yang diikuti oleh huruf yang sama pada kolom yang sama menunjukkan tidak berbeda nyata p: Duncan 5\%.

$*$

: Berasal dari larva $S$. litura

Myf B :Wildtype (berasal dari larva S. litura)

Myf 1 : Mutan dari iradiasi ion beam

Myf 42 : Mutan dari iradiasi gamma ray

Myf 51 : Mutan dari iradiasi gamma ray

hsi : hari setelah inokulasi 
Tabel 2. Kerapatan konidia M. anisopliae s.l. * pada media PSA

Isolat M. anisopliae s.l. *

Myf B
Myf 1
Myf 42
Myf 51
ka y ang diikuti oleh huruf y
berbeda ny ata pada Uji Dunc
ari larva $S$. litura
(berasal dari larva $S$. litura )
ari iradiasi ion beam
ari iradiasi gamma ray
ari iradiasi gamma ray

Kerapatan konidia (x $\left.10^{6} \mathrm{konidia} / \mathrm{ml}\right)$
$18,20 \mathrm{~b}$
11,15 a
$18,70 \mathrm{~b}$
$19,60 \mathrm{~b}$

\footnotetext{
sama menunjukkan tidak berbeda ny ata pada Uji Duncan 5\%.

* $\quad$ : Berasal dari larva $S$. litura

Myf B :Wildtype (berasal dari larva S. litura)

Myf 1 : Mutan dari iradiasi ion beam

Myf 42 : Mutan dari iradiasi gamma ray

Myf 51 : Mutan dari iradiasi gamma ray
}

Keterangan : Angka-angka y ang diikuti oleh huruf yang sama pada kolom yang

meskipun relatif rendah dari isolat MyfB (wildtype). pada isolat Myf 51 relatif tinggi dari isolat Myf B, Berdasarkan hasil DMRT 5\%, kerapatan konidia isolat berbeda halnya dengan Myf 1 daya kecambah Myf 51 dan Myf 42 (mutan) masing-masing tidak konidianya relatif rendah dari isolat MyfB. Sedangkan berbeda nyata dengan isolat Myf B daya kecambah konidia isolat Myf 42 relatif sama (wildtype).Sedangkan isolat Myf 1 (mutan) berbeda dengan isolat Myf B. Berdasarkan hasil DMRT 5\%, nyata dengan isolat Myf B (wildtype) (Tabel 2). daya kecambah konidia isolat Myf 51 dan Myf 1

Dari hasil perhitungan daya kecambah konidia berbeda nyata dengan isolat Myf B. Sedangkan isolat M. anisopliae s.l.* menunjukkan bahwa isolat Myf Myf 42 tidak berbeda nyata dengan isolat MyfB (Tabel 51, Myf 42, dan Myf 1 mampu berkecambah normal 3). sebagaimana isolat Myf B. Daya kecambah konidia

Tabel 3. Daya kecambah konidia M. anisopliae s.l. * yang telah diinkubasi selama 16 jam pada media PSA

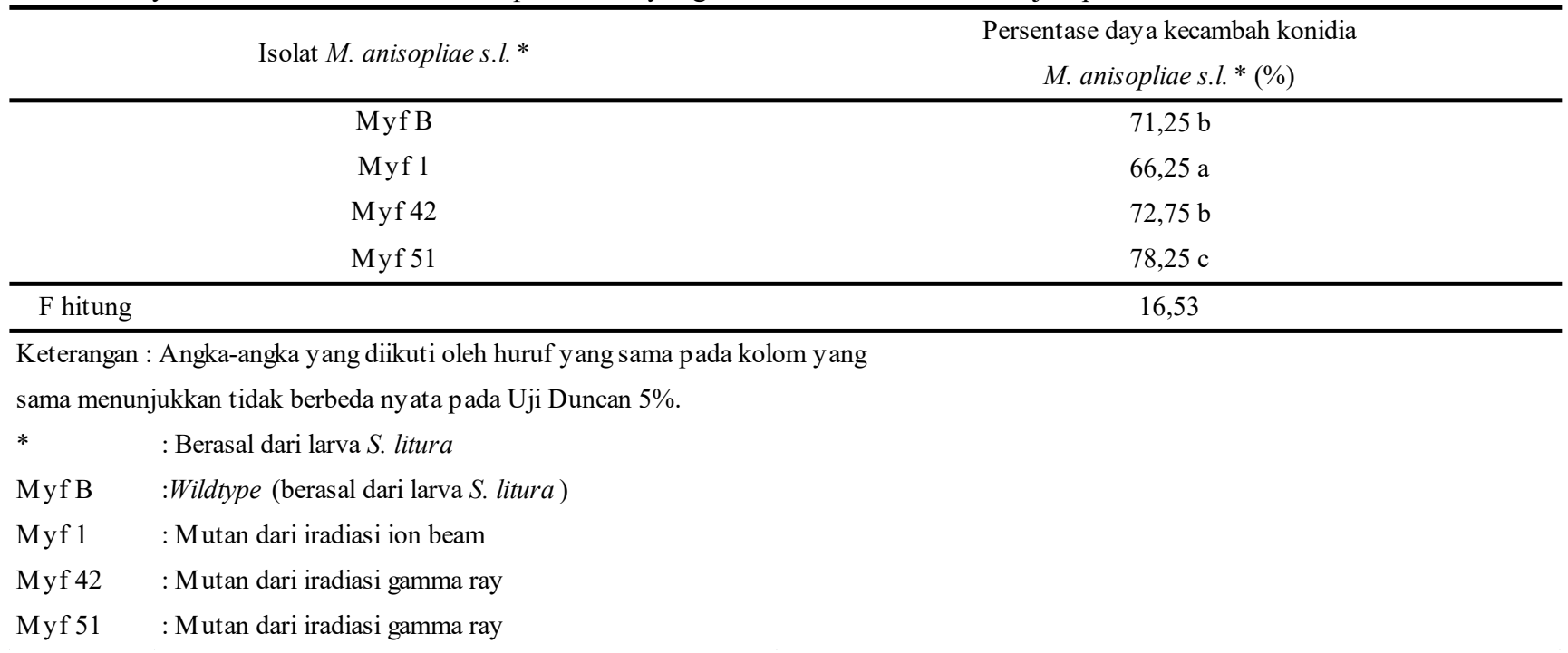


Tabel 4. Hasil analisis probit LC50 isolat Myf B vs Myf 51 terhadap ulat api

\begin{tabular}{|c|c|c|c|}
\hline Isolat & $\begin{array}{c}\mathrm{LC}_{50} \\
\text { (konidia/ml) }\end{array}$ & Batas Bawah & Batas Atas \\
\hline MyfB & $2,92 \times 10^{5}$ & - & - \\
\hline Myf 51 & $1,06 \times 10^{5}$ & - & - \\
\hline
\end{tabular}

Berdasarkan hasil analisis probit isolat MyfB (wildtype) dan Myf 51 (mutan), $\mathrm{LC}_{50}$ isolat Myf 51 terhadap ulat api sebesar $1,06 \times 10^{5} \mathrm{konidia} / \mathrm{ml}$. Sedangkan $\mathrm{LC}_{50}$ isolat Myf B terhadap ulat api sebesar $2,92 \times 10^{5} \mathrm{konidia} / \mathrm{ml}$. Hal ini menunjukkan bahwa isolat Myf 51 (mutan) dan MyfB (wildtype) pada konsentrasi tersebut efektif mematikan ulat api sebanyak 50\% (Tabel 4).

Dari hasil perhitungan $\mathrm{LT}_{50}$ isolat MyfB dan Myf 51, LT $_{50}$ isolat Myf 51 (mutan) tidak berbeda nyata dengan isolat Myf B (wildtype) pada masingmasing konsentrasi. Hal ini menunjukkan bahwa isolat Myf 51 (mutan) dan Myf B (wildtype) mampu mematikan $50 \%$ ulat api dalam waktu yang relatif sama(Tabel 5).
Pada pengamatan ulat api 7 hari setelah aplikasi dapat dilihat bahwa ulat api yang diberi perlakuan Myf 51 (mutan) ditumbuhi miselia lebih banyak dibandingkan ulat api yang diberi perlakuan MyfB (wildtype). Ulat api yang tidak diberi perlakuan (kontrol) tidak terinfeksi sehingga ulat api tidak mengalami kematian dan dapat berkembang menjadi pupa dan ngengat. Sedangkan ulat api yang diberi perlakuan Myf B (wildtype) dan Myf 51 (mutan) mengalami kematian dan tidak ada yang berkembang menjadi pupa dan ngengat (Gambar $1)$.

Hasil uji pertumbuhan dan perkembangan $M$. anisopliae s.l. (mutan vs wildtype) secara in vitromenunjukkan bahwa isolat mutan Myf 51, Myf 42, dan Myf 1 mampu tumbuh dan berkembang normal

Tabel 5. Hasil analisis probit $\mathrm{LT}_{50}$ isolat Myf $\mathrm{B}$ vs Myf 51 terhadap ulat api

\begin{tabular}{ccccc}
\hline Isolat & Konsentrasi (konidia/ml) & $\begin{array}{c}\text { LT50 } \\
\text { (hsa) }\end{array}$ & Batas Bawah & Batas Atas \\
\hline Myf B & $3,25 \times 10^{5}$ & 6,6 & 6,0 & 7,7 \\
Myf 51 & $3,75 \times 10^{5}$ & 6,1 & 5,6 & 6,9 \\
Myf B & $1,00 \times 10^{6}$ & 6,3 & 5,8 & 7,2 \\
Myf 51 & $1,10 \times 10^{6}$ & 5,7 & 5,2 & 6,3 \\
Myf B & $2,10 \times 10^{6}$ & 5,9 & 5,4 & 6,5 \\
Myf51 & $2,55 \times 10^{6}$ & 5,2 & 4,8 & 5,7 \\
Myf B & $3,05 \times 10^{6}$ & 5,5 & 5,0 & 6,2 \\
Myf51 & $3,35 \times 10^{6}$ & 5,1 & 4.6 & 5,6 \\
Myf B & $4,55 \times 10^{6}$ & 5,3 & 4,9 & 6,0 \\
Myf 51 & $4,90 \times 10^{6}$ & 4,6 & 4,2 & 5,0 \\
\hline
\end{tabular}


sebagaimana isolat Myf B (wildtype). Hal tersebut dibuktikan dengan pertumbuhan koloni, kerapatan konidia, dan daya berkecambah konidia isolat Myf 51 (mutan) yang relatif tinggi dari isolat MyfB (wildtype). Pertumbuhan koloni, kerapatan konidia, dan daya berkecambah konidia isolat Myf 42 (mutan) yang relatif sama dengan isolat Myf B (wildtype). Sedangkan pertumbuhan koloni, kerapatan konidia, dan daya berkecambah konidia isolat Myf 1 (mutan) relatif rendah dari isolat MyfB (wildtype) (Tabel 1, Tabel 2, Tabel 3).

Isolat Myf 51 (mutan) memiliki kerapatan konidia atau konsentrasi yang relatif tinggi dibandingkan dengan isolat Myf B (wildtype)sehingga untuk menginfeksi ulat api memiliki peluang yang cukup tinggi. Hal ini dibuktikan oleh penelitian Rustama (2008) yang menunjukkan bahwa semakin tinggi kerapatan konidia yang diinfeksikan, maka semakin tinggi peluang kontak antara patogen dengan inang.

Berdasarkan hasil analisis probit $\mathrm{LC}_{50}$ isolat Myf B (wildtype) dan Myf 51 (mutan) (Tabel 4), nilai
$\mathrm{LC}_{50}$ isolat Myf51 relatifkecil dibandingkan isolat Myf B. Isolat Myf 51 mampu mematikan ulat api lebih banyak dibandingkan isolat MyfB. Hal ini menunjukkan bahwa semakin kecil nilai $\mathrm{LC}_{50}$ suatu cendawan entomopatogen maka semakin beracun cendawan entomopatogen tersebut terhadap ulat api.

Berdasarkan hasil analisis probit $\mathrm{LT}_{50}$ isolat Myf B (wildtype) dan Myf 51 (mutan) (Tabel 5), isolat Myf 51 (mutan) dan MyfB (wildtype) membutuhkan waktu yang relatif sama dalam menimbulkan kematian terhadap ulat api. Waktu yang dibutuhkan untuk menyebabkan kematian serangga uji bervariasi tergantung pada virulensi patogen, sifat resistensi inang, dan kondisi lingkungan mikro di tubuh inang (Pachamuthu et al., 1999). Dari penelitian diketahui bahwa konsentrasi yang relatif cepat membunuh 50\% ulat api ialah4,90 x $10^{6} \mathrm{konidia} / \mathrm{ml}$ dengan waktu kematian 4,6 hari setelah aplikasi (Tabel 5).

Pada pengamatan mortalitas ulat api secara visual, ulat api pada 3 hari setelah kematian tampak mengalami mumifikasi dan permukaan tubuhnya

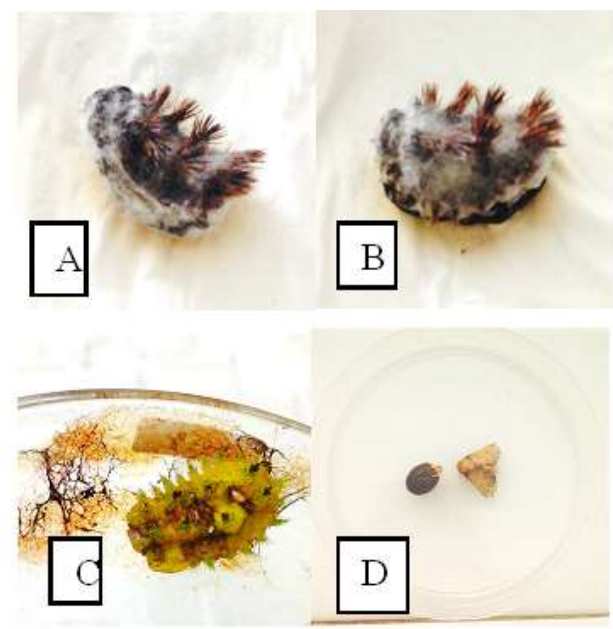

Gambar 1. Ulat api.A. perlakuan Myf B (wildtype); B. perlakuan Myf 51 (mutan); C. tanpa perlakuan (kontrol); D. pupa dan ngengat dari ulat api tanpa perlakuan (kontrol) 


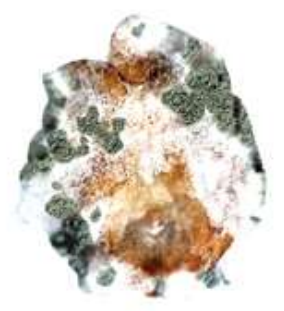

Gambar 2. Ulat api secara mikroskopis pada 5 hari setelah kematian

ditumbuhi miselia berwarna putih. Pada 5 hari setelah kematian miselia berubah menjadi berwarna hijau (Gambar 2).Miselia yang tumbuh pada ulat api yang terinfeksi Myf 51 (mutan) lebih banyak dibandingkan ulat api yang terinfeksi Myf B (wildtype). Hal ini dikarenakan pada isolat Myf 51 jumlah konidia yang dihasilkan lebih banyak dibandingkan isolat Myf B.Menurut Tampubolon et al. (2013), pemberian konsentrasi $M$. anisopliae yang tinggi mengakibatkan jumlah konidia yang masuk ke dalam tubuh serangga semakin banyak, dibandingkan dengan perlakuan yang jumlah konidianya lebih sedikit.

\section{KESIMPULAN}

Dari hasil penelitian dapat diambil kesimpulan sebagai berikut.Isolat mutan Metarhizium anisopliaes.l. Myf 51, Myf 42, dan Myf 1 pada media PSA mampu tumbuh dan berkembang normal sebagaimana isolat Myf B (wildtype). Diameter isolat Myf 51 berbeda nyata dengan isolat Myf B, sedangkan isolat Myf 42 dan Myf 1 tidak berbeda dengan isolat Myf B. Kerapatan konidia isolat Myf 51 dan Myf 42 berbeda nyata dengan isolat Myf $\mathrm{B}$, sedangkan isolat Myf 1 tidak berbeda dengan isolat Myf B. Daya kecambah isolat Myf 1 dan Myf 51 berbeda dengan isolat Myf, sedangkan isolat Myf 42 tidak berbeda dengan isolat Myf B.Isolat M. anisopliae s.l. Myf 51 (mutan) dan Myf B (wildtype) efektif mengendalikan ulat api dengan nilai $\mathrm{LC}_{50} \mathrm{Myf} 51$ sebesar 1,06 x $10^{5}$ konidia/ml dan LC ${ }_{50}$ MyfB sebesar 2,92 x $10^{5}$ konidia/ ml. $\mathrm{LT}_{50}$ Myf 51 dan $\mathrm{LT}_{50}$ Myf B terhadap ulat api relatif sama, yaitu pada kisaran 4,6 - 6,6 hari setelah aplikasi (hsa).

\section{DAFTAR PUSTAKA}

Buana, L. dan J. Siahaan. 2003. Ulat Pemakan Daun Kelapa Sawit. Warta Pertemuan Teknis Kelapa Sawit21 : 56 - 77.

Desyanti, Y.S.Hadi, S. Yusuf, dan T. Santoso. 2007. Keefektifan Beberapa Spesies Cendawan Entomopatogen untuk Mengendalikan Rayap Tanah dengan Metode Kontak. Jurnal Ilmu dan Teknologi Kayu Tropis.2(5) : 68 - 77.

Espinel-Ingroff, A. 2000. Germinated and Non Germinated Conidial Suspensions for Testing of Susceptibilities of Aspergillus spp. to Amphotericin B, Itraconazole, Posaconazole, Rafuconazole, and Voriconazole. Jurnal Antimicrobial Agents and Chemotherapy 45(2) : $605-607$. 
Fitrah, Y.D. 2009. Patogenisitas cendawan entomopatogen Metarhiziumsp. mutan ultra violet terhadap Crocidolomia pavonana fabricius (Lepidoptera: Pyralidae). (Skripsi). Universitas Andalas. Padang. $131 \mathrm{hlm}$.

Pachamuthu, P., S.T. Kamble, and G.Y. Yuen. 1999. Virulence of Metarhizium anisopliae (Deuteromycotina: Hyphomycetes) strain ESC-1 to German cockroach (Dictyoptera: Blattellidae) and its compatibility with insecticides. Journal Economic Entomology.92:340- 346.

Prawirosukarto, S., R.Y. Purba, C. Utomo, dan A. Susanto. 2003. Pengenalan dan Pengendalian Hama dan Penyakit Tanaman Kelapa Sawit. Pusat Penelitian Kelapa Sawit. Pematang Siantar. 112 hlm.

Ratna, Y. 2004. Kajian Kualitas Spora Metarhizium

sp. pada Berbagai Jenis Media dan Lama
Penyimpanan.Jurnal Agronomi 8(1): 59-62.

sp. pada Berbagai Jenis Media dan Lama
Penyimpanan.Jurnal Agronomi 8(1): 59 - 62.
Rustama, M.M. 2008. Patogenisitas Jamur Entomopatogen Metarhizium anisopliae terhadap Crocidolomia pavonana Fab.Lembaga Penelitian Universitas Padjadjaran. Bandung. $77 \mathrm{hlm}$.

Susanto, A., A.E. Prasetyo, D. Simanjuntak, T.A.P. Rozziansha, H. Priwiratama, Sudharto, R.D. Chenon, A. Sipayung, A.T. Widi, dan R.Y. Purba. 2012. EWS Ulat Kantong, Ulat Api, Ulat Bulu. Pusat Penelitian Kelapa Sawit. Pematang Siantar. $179 \mathrm{hlm}$.

Tampubolon, D.Y., Y. Pangestiningsih, F. Zahra, dan F. Manik. 2013. Uji Patogenisitas Bacillus thuringiensis dan Metarhizium anisopliae terhadap Mortalitas Spodoptera litura Fabr (Lepidoptera: Noctuidae) di Laboratorium. Jurnal Online Agroekoteknologi. 1(3) : 784 - 791. 